\title{
All-Trans and 9-Cis Retinoic Acid Induction of CRABPII Transcription Is Mediated by RAR-RXR Heterodimers Bound to DR1 and DR2 Repeated Motifs
}

\author{
Beatrice Durand, Michael Saunders, Pierre Leroy, \\ Mark Leid, and Pierre Chambon \\ Laboratoire de Génétique Moléculaire des Eucaryotes \\ du Centre National de la Recherche Scientifique \\ Unité 184 de Biologie Moléculaire et de Génie \\ Génétique de l'Institut National de la Santé \\ et de la Recherche Médicale \\ Institut de Chimie Biologique \\ Faculté de Médecine \\ 11 rue Humann \\ 67085 Strasbourg-Cédex \\ France
}

\section{Summary}

Two cooperating retinoic acid response elements (RAREs) in the cellular retinoic acid-binding protein II (CRABPII) gene mediate differential transcriptional transactivation by retinoic acid receptors (RARs) and retinoid X receptors (RXRs) in P19 embryonal carcinoma cells. RARE1 and RARE2 are direct repeats (DR) of two motlfs separated by 2 bp (DR2) and 1 bp (DR1), respectively, and bind RAR-RXA hoterodimers more efficlently then homodimers. Using all-trans and 9-cis RA, which differentially activate RARs and RXRs, and RAR and RXR dominant-negative mutents, RAR-RXR heterodimers bound to RARE1 and RARE2 are shown to be responsible for CRABPII promoter transactivation, arguing against a unique DA spacing specifying recognition by RARs. Within heterodimers, RAR and RXR independently and differentially transactivate, depending on the specific RARE. Consistent with theee results, 9-cis RA increases CAABPII mRNA levele more effleiently than all-trans RA. In contrast, alltrans and 9-cis RA have identical effects on induction of RARB2 trenscripts.

\section{Introduction}

Retinoids appear to play a major role in embryogenesis, differentiation, and homeostasis (for reviews see Lotan, 1980; Sherman, 1986; Brockes, 1989, 1990; Saurat, 1990; Summerbell and Maden, 1990; Tabin, 1991; Mendelsohn et al., 1992). Three classes of proteins bind retinoids with high affinity: nuclear receptors that belong to the superfamily of steroid/thyroid receptors (for reviews see Evans, 1988; Green and Chambon, 1988; Beato, 1989), the cellular retinoic acid-binding proteins I (CRABPI) and II (CRABPII), and the cellular retinol-binding proteins I (CRBPI) and II (CRBPII) (for review see Bailey and Siu, 1988; Stoner and Gudas, 1989; Blomhoff et al., 1991; Chytil and Stump, 1991; Giguère et al., 1990; Maden, 1991). The three types of retinoic acid receptors (RARs), RAR $\alpha, \beta$, and $\gamma$ (for review see Chambon et al., 1991; de Luca, 1991; Ruberte et al., 1991a; Kastner et al., 1992; Leroy et al., 1992), and the three types of retinoid X receptors (RXRs), $R \times R \alpha, \beta$, and $\gamma$ (Hamada et al., 1989; Mangelsdort et al., 1990, 1992; Rowe et al., 1991; Blumberg et al., 1992; Leid et al., 1992), are ligand-inducible trans regulators that modulate the transcription of target genes by interacting with cis-acting DNA retinoic acid response elements (RAREs). At the present time, there are only a limited number of RAREs that have been fully identified by mutagenesis in the regulatory region of "natural" target genes whose expression has been established to be controlled by retinoic acid (RA) at the transcriptional level. These natural RAREs appear to consist of a direct repeat (DR) of two core motifs (5'-PuG [G/ T]TCA or a closely related sequence) separated by either 5 bp (DR5) in the case of human and mouse RARa2 (mRARa2) (Leroy et al., 1991a) and RARB2 (mRARß2) genes (de Thé et al., 1990; Sucov et al., 1990), 2 bp (DR2) in the case of the mouse CRBPI gene (Smith et al., 1991), or $4 \mathrm{bp}$ (DR4) and $13 \mathrm{bp}$ in the case of the mouse laminin B1 gene (Vasios et al., 1989, 1991). In addition, studies performed with a putative natural RXRE (Mangelsdorf et al., 1991) and synthetic RAREs (Kliewer et al., 1992a; Mader et al., 1992) have shown that RXRs preferentially bound to repeated core motifs separated by 1 bp (DR1).

Cotransfection experiments using expression vectors for either natural or chimeric RARs and RXRs and synthetic responsive promoters have revealed that RARs are efficiently actlvated by either all-trans RA or 9-cis RA at a ligand concentration of $50 \mathrm{nM}$, whereas $R \times R$ s are efficiently activated only by 9 -cis $R A$ at this ligand concentration. However, RXRs can also be activated by all-trans RA at higher concentrations $(1-10 \mu \mathrm{M})$, most probably owing to an all-trans RA to 9-cis RA conversion (Heyman et al., 1992; Levin et al., 1992; M. T. Bocquel et al., unpublished data; and see below). Interestingly, RARs and RXRs bind much more efficiently as RAR-RXR heterodimers to natural and synthetic RAREs in vitro irrespective of the length of the spacer separating the repeated motifs ( $\mathrm{Yu}$ et al., 1991; Kliewer et al., 1992b; Leid et al., 1992; Zhang et al., 1992; Marks et al., 1992; Bugge et al., 1992). Moreover, transfection experiments using RAR and RXR expression vectors together with either synthetic (Kliewer et al., 1992b; Zhang et al., 1992) or putative natural (Marks et al., 1992) RA responsive promoters have suggested that RAR-RXR heterodimers may be functionally active.

A number of interesting questions remain to be addressed. What is the extent of RARE polymorphism with regard to the spacing of the directly repeated motifs? Are RAR-RXR heterodimers truly responsible for mediating the retinoid-induced transcriptional response of natural target genes in vivo, irrespective of this spacing? Can the two members of RAR-RXR heterodimeric complexes bound to a natural RARE in vivo be activated independently, and what are the respective roles of all-trans RA and 9-cis RA in RAR-RXR-mediated transactivation? How does the spacing of the directly repeated motifs affect transactivation by the two heterodimer partners? 


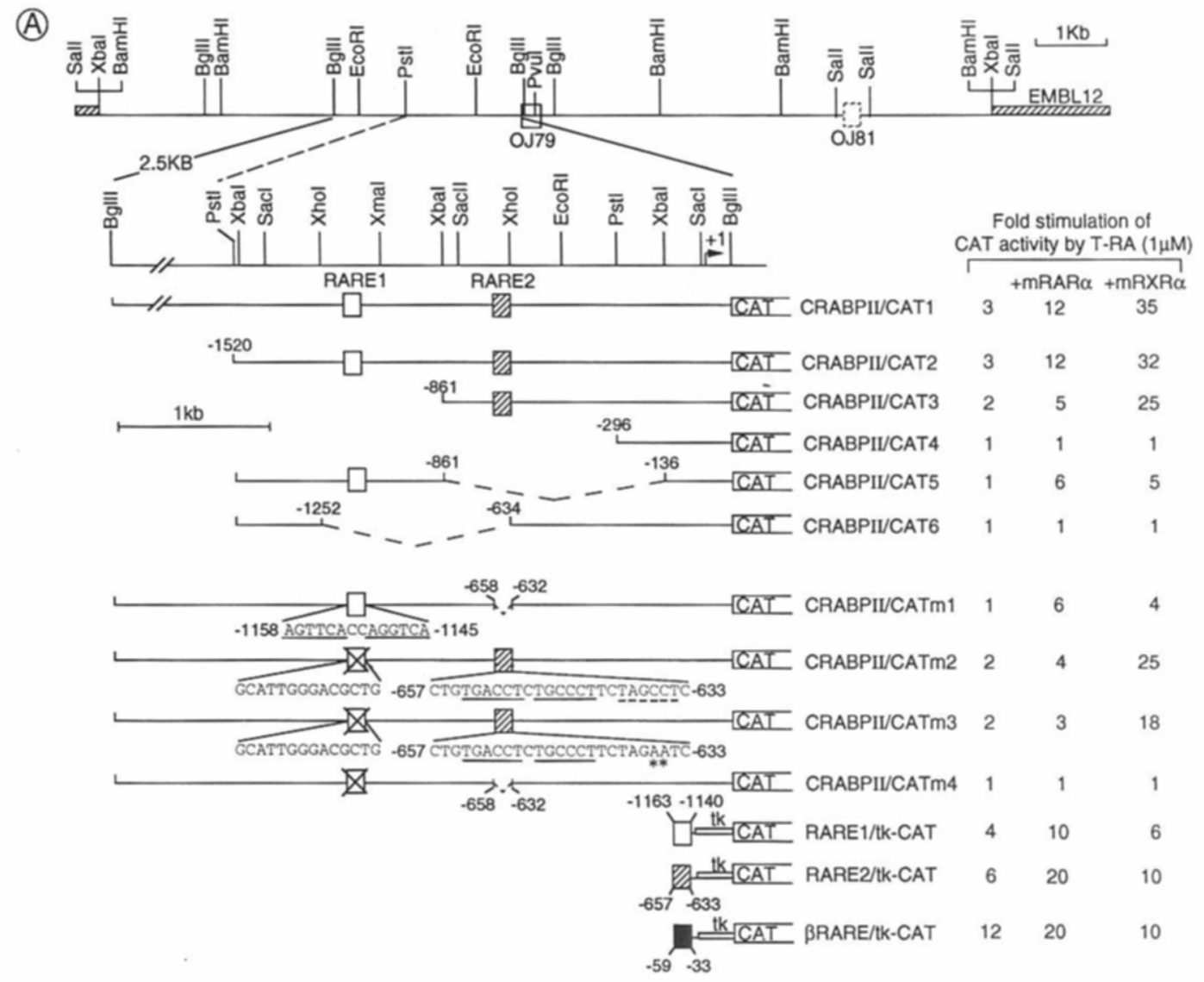

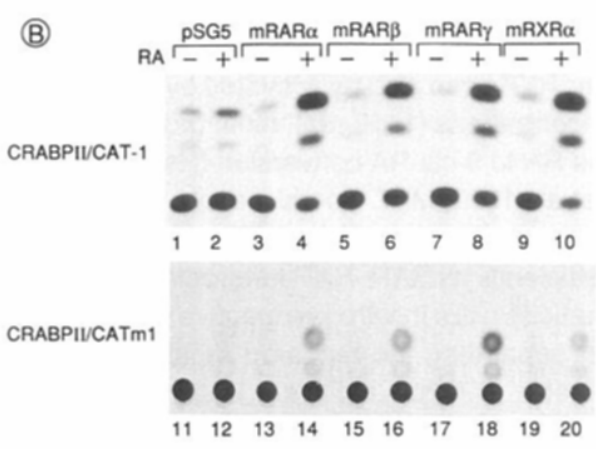

CRABPII/CATm2

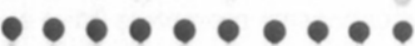

$\begin{array}{llllllllll}21 & 22 & 23 & 24 & 25 & 26 & 27 & 28 & 29 & 30\end{array}$

CRABPIIICATM4

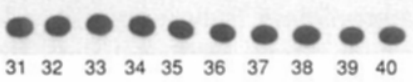

Figure 1. mCRABPII Promoter Activity and Identification of Two RAREs

(A) Schematic representation of the CRABPII gene and of the reporter CAT constructs with the corresponding fold stimulation of CAT activity. The limits of the first and the last exons are represented by boxes, each of them localized by hybridization with the 0.579 and 0.581 probes, respectively (see Experimental Procedures), and relevant restriction sites are indicated. Coordinates are given with respect to the start site (+1) (see Figure 2). The open and hatched boxes correspond to the indicated sequences and the closed box to the sequence $5^{\prime}$-GGTAGGGTTCACCGAAAGTTCACTCG-3' of the RARB2 gene RARE. The broken underlining in CRABPII-CATm1 (nucleotides -635 to-639) denotes a related degenerate motif, into which two point mutations were introduced (indicated by asterisks) to generate CRABPIICATm3. The fold stimulation of CAT activity was calculated taking as 1 the activity in the absence of all-trans RA (T-RA) and cotransfected receptor. CRABPII-CAT constructs were transfected in P19 EC cells whereas the TK-CAT (tk-CAT) constructs were transfected in HeLa cells to avoid the RA induction of the TK-CAT reporter itself that occurs in P19 cells (results in the two cell types were qualitatively similar). The fold stimulations correspond to average values of several independent experiments ( $\pm 20 \%$ ).

(B) CAT activity of CRABPII promoter constructs. P19 EC cells were transfected with $10 \mu \mathrm{g}$ of the indicated reporter vector and $500 \mathrm{ng}$ of either mRAR $\alpha 1, \beta 2, \gamma 1, m R X R \alpha$, or parental expression vector (pSG5). All-trans RA $(1 \mu \mathrm{M})$ was added as indicated $16 \mathrm{hr}$ later, cells were harvested $24 \mathrm{hr}$ later, and CAT assays were performed. 


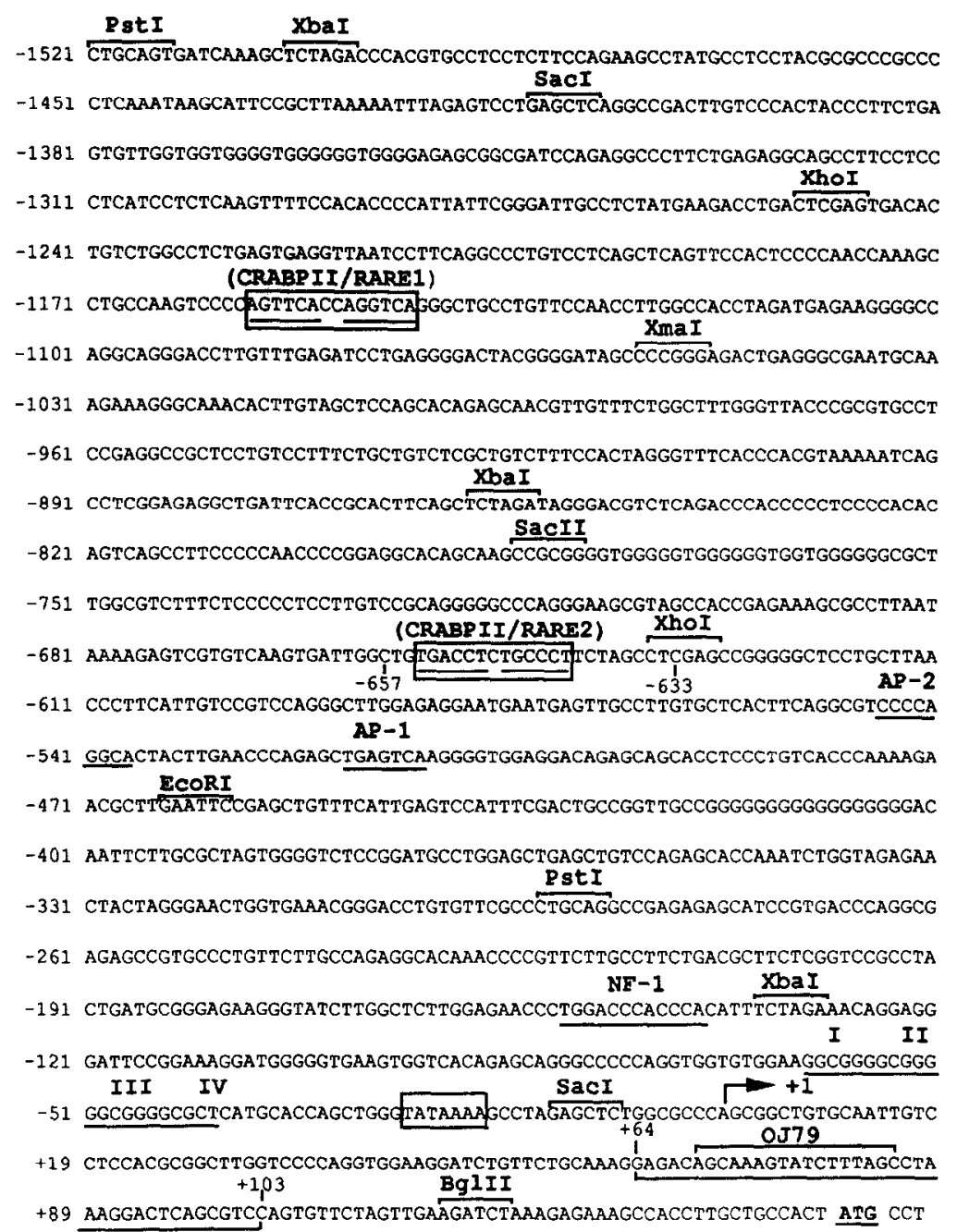

Figure 2. Sequence of the mCRABPII Promoter Region

The sequence of the 1640 bp Pstl-Bglli 5 ' flanking fragment of the mCAABPI gene is shown, with +1 corresponding to the predominant transcription stant site. Relevant restriction sites are indicaled. Underlined are $\left(5^{\prime} \rightarrow 3\right)$ the two RARES (CRABPII-AARE 1 and CRABPIIRARE2); putative AP-2-, AP-1-, and nuclear factor 1 (NF-1)-binding sites; and four potential Sp1-binding sites (labeled from I to IV). The TATA box is boxed. The sequence of the oligonucleotide used for primer extention is underlined.
The expression of the CRABP genes has been reported to be stimulated by RA (Wei et al., 1989; Giguère et al., 1990). In particular, it has been shown that the level of CRABPII messenger RNA (mRNA) is increased in F9 teratocarcinoma cells by treatment with $R A 10^{-7} \mathrm{M}$ (Giguère et al., 1990), in human skin by topical application of RA (Siegenthaler and Saurat, 1990; Aström et al., 1991), and in lesional hyperplastic psoriatic skin (Didierjean et al., 1991; Elder et al., 1992). In the present study, we have isolated and functionally dissected the promoter region of the mouse CRABPII (mCRABPII) gene in an attempt to answer the above questions. We have characterized two cooperating response elements of DR2 and DR1 type that can independently mediate differential activation by RAR and RXR in transfected P19 embryonal carcinoma (EC) cells. We show that RAR and RXR bind cooperatively to these DR2 and DR1 elements in vitro, and we demonstrate that RAR-RXR heterodimers bound to these elements actually mediate RA induction of the CRABPII promoter in P19 EC cells. We also provide evidence for independent transactivation by the two members of the heterodimeric complex, as well as evidence against the view that the length of the spacer between the repeated motifs provides a code that specifies recognition of the response elements by RARs and RXRs in vivo. Finally, consistent with transfection experiment results, we show that 9-cis RA is more efficient than all-trans RA at increasing the level of CRABPII mRNA in P19 cells.

\section{Results}

\section{Putative Promoter Elements in the mCRABPII Gene 5' Flanking Region}

A single recombinant $\lambda E M B L 12$ phage containing an insert of $\sim 12 \mathrm{~kb}$ was isolated by screening a mouse genomic library with a full-length mCRABPII CDNA probe (Giguère et al., 1990; see Experimental Procedures). This recombinant hybridizes with two synthetic oligonucleotides (OJ79 and OJ81; Figure 1A and Figure 2) corresponding, respectively, to the $5^{\prime}$ and $3^{\prime}$ untranslated region of the cDNA and therefore contains the complete coding sequence of the mCRABPII gene. Further analysis of this phage by a combination of restriction mapping using a unique Pvul site present in the mCRABPII cDNA and Southern blotting with OJ79 and OJ81 probes identified a Bglll fragment of 2.5 $\mathrm{kb}$ extending into the $5^{\prime}$ flanking region of the gene (Figure 


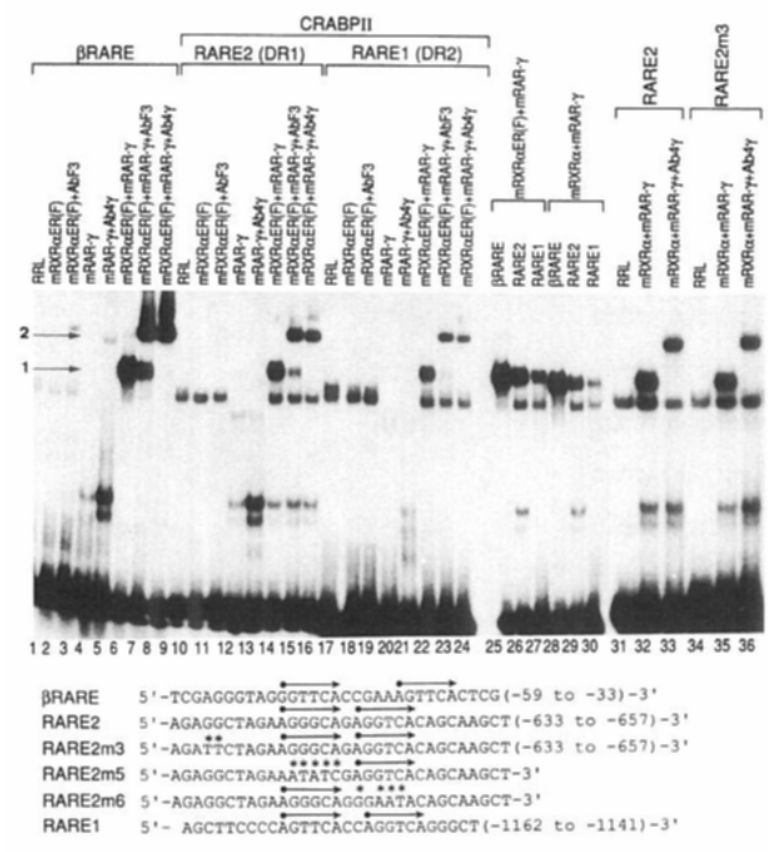

Figure 3. Binding of Heterodimers of mRAR $\gamma$ and mRXR $\alpha$ to $\beta R A R E$, CRABPII-RARE2, CRABPII-RARE1, and Mutated CRABPII-RARE2 Gel retardation assays are shown in which $\mathrm{mRXRaER}(\mathrm{F})(\sim 10 \mathrm{fmol}$ translated in vitro), mRAR $(\sim 10 \mathrm{fmol}$ translated in vitro), and $m R \times R \alpha$ $\left(\sim 10 \mathrm{fmol}\right.$ translated in vitro) were incubated as indicated with ${ }^{32} \mathrm{P}-5$ end-labeled oligonucleotides ( $\sim 20 \mathrm{fmol}$ at $\sim 50,000 \mathrm{cpm}$ ) corresponding to BRARE, CRABPII-RARE2, CRABPII-RARE1, and mutated CRABPII-RARE2(RARE2m3, RARE2m5, RARE2m6). (The sequence of the upper strand of each probe is given.) No binding of any combination of receptors was observed in the case of RARE2m5 and RARE2m6 (data not shown). Lanes 31-36 correspond to a different experiment than do lanes 1-30. Supershifted complexes were observed in the presence of specific antibodies, AbF3 for mRXRaER(F) (lanes 7, 15, and 23) and $A b 4 \gamma$ for mRARy (lanes 8, 16, 24, 33, and 36). Arrow 1 indicates the position of specific retarded RARE-receptor complexes, and arrow 2 indicates the position of antibody supershifted complexes. RRL, control assays with unprogrammed rabbit reticulocyte lysate (lanes 1, 17, and 31).

1A). The sequence of a 1650 bp Pstl-Bgill fragment 5 ' to the ATG initiator codon was determined (Figure 2). As expected, its $3^{\prime}$ extremity overlaps with the $5^{\prime}$ untranslated region of the cloned mCRABPII cDNA sequence (Giguere et al., 1990).

Primer extension using an oligonucleotide complementary to nucleotides +64 to +103 (underlined in Figure 2) was performed on poly(A) ${ }^{+}$RNA prepared from P19 EC cells treated with $1 \mu \mathrm{M}$ all-trans RA for $24 \mathrm{hr}$. A major extension product was detected whose $3^{\prime}$ end mapped at the position indicated at +1 in Figure 2 (data not shown). This mapping is in agreement with the presence of a canonical TATA box (Corden et al., 1980), 26 bp upstream of the mRNA start site. The mCRABPII $5^{\prime}$ flanking region contains several overlapping putative binding sites for the transcription factor Sp1 between nucleotides -41 to -62 (5'-GGCGGG-3', underlined and labeled as I to IV in Figure 2; Briggs et al., 1986), a sequence related to the nuclear factor 1 binding motif (5'-TGGN 7 CCA-3', from nucleotides -152 to -141 ; Chodosh et al., 1988; Santoro et al., 1988), a perfect AP-1 binding site (5'-TGAGTCA-3', from nucleotides -520 to -514 ; Angel et al., 1987), and an AP-2 binding site (CCCCAGGCA, from nucleotides -546 to -538 ; Imagawa et al., 1987; Mitchell et al., 1987). No sequence homology was found between this promoter sequence and those of mCRABPI (Wei et al., 1990, 1991), mouse CRBPI (Smith et al., 1991), and rat or mouse CRBPII (Demmer et al., 1987; $\mathrm{H}$. Nakshatri et al., unpublished data).

\section{The mCRABPII Promoter Contains Two Functional DR1 and DR2 RAREs That Bind RAR-RXR Heterodimers In Vitro Much More Efficiently Than RAR or RXR Homodimers}

Various lengths of the putative mCRABPII promoter region were, with or without internal deletions, ligated to the chloramphenicol acetyltransferase (CAT) gene (see Figure 1A). These constructs were tested for CAT expression and alltrans RA $(1 \mu \mathrm{M})$ inducibility, following transfections into P19 EC cells together with $500 \mathrm{ng}$ of expression vectors coding either for mRAR $\alpha 1, \beta 2$, or $\gamma 1$ or for mouse RXR (mRXR) $\alpha, \beta$, or $\gamma$. In the presence of the parental expression vector $\mathrm{PSG}$, the all-trans RA inducibility of CRABPIICAT1 in P19 cells was 2- to 3-fold (see Figures $1 A$ and $1 B)$. When either mRAR $\alpha, \beta$, or $\gamma$ expression vectors were cotransfected with this reporter, a 10- to 14-fold increase in CAT activity was observed in the presence of all-trans RA, whereas a 30- to 40-fold induction was seen with either $m R X R \alpha$ or $m R X R \gamma$ and a 15- to 20-fold induction was seen with $\operatorname{mRXR} \beta$ (see Figures $1 \mathrm{~A}$ and $1 B$; data not shown). Progressive $5^{\prime}$ to $3^{\prime}$ deletions resulted in a two step decrease of all-trans RA inducibility. The first decrease corresponded to deletion of the -1520 to -861 sequence (compare CRABPII-CAT2 and CRABPII-CAT3; see Figure 1A), and the second decrease occurred when the -861 to -296 sequence was deleted (compare CRABPII-CAT3 and CRABPII-CAT4). The construct containing an internal deletion between -861 and -136 in CRABPII-CAT2 was still inducible (6-fold for mRAR $\alpha$ and 5-fold for $m R X R a$ ), but no induction was seen when the -1252 to -634 sequence was deleted. Thus, the CRABPII promoter appears to contain two all-trans RAREs, one located between positions -1252 and -861 and the other located between positions -861 and -634 . Interestingly, in $P 19$ cells these two elements clearly exhibit a different reactivity toward the RAR and RXR families.

Two DNA sequences that show homology with the RAREs previously described in the literature (see Introduction) were identified and named RARE1 and RARE2 (boxed in Figure 2). RARE1 is a DR of two core motifs separated by 2 bp (DR2; see Introduction; 5'-AGTTCAccAGGTCA-3', nucleotides -1158 to -1145 ), and RARE2 is a DR of two core motifs separated by 1 bp (DR1; 5'-TGACCTcTGCCCT-3', nucleotides -654 to -642; 5'-AGGGCAgAGGTCA-3', on the complementary strand). We mutated RARE1 in CRABPII-CAT1, thereby creating CRABPIICATm2, and deleted bases -633 to -657 in RARE2 of CRABPII-CAT1, creating CRABPII-CATm1 (see Figure $1 A)$. The deletion of bases -633 to -657 eliminates the repeated motifs of RARE2 and a related degenerate motif 5'-TAGCC-3' (nucleotides -635 to -639 ). The latter motif 
was mutated in CRABPII-CATm2 to 5'-TAGAA-3', yielding CRABPII-CATm3, which exhibited the same all-trans RA pattern of inducibility as CRABPII-CATm2 (see Figure 1A; data not shown). CRABPII-CATm4, in which both RAREs were destroyed (see Figure 1A), was not inducible by all-trans RA, whereas CRABPII-CATm1 and CRABPIICATm2 showed the same pattern of inducibility as CRABPII-CAT5 and CRABPII-CAT3, respectively. These results strongly suggest that RARE 1 and RARE2 are responsible for all-trans RA response of the CRABPII promoter (see Figures $1 A$ and $1 B$; data not shown).

RARE1 and RARE2 were ligated in their natural orientation in PBLCAT2 $^{+}$upstream of the herpes simplex virus thymidine kinase (TK) promoter to investigate whether they could confer all-trans RA inducibility on an heterologous promoter (RARE1-TK-CAT and RARE2-TK-CAT in Figure 1A). The all-trans RA inducibility of these reporter genes was investigated in HeLa cells cotransfected with pSG5 or $500 \mathrm{ng}$ of expression vectors coding for either mRAR $\alpha 1, \beta 2, \gamma 1$, or $m R X R \alpha$. Similar transfections were performed with the $B$ RARE-TK-CAT reporter containing the RARE present in the human and mouse RARB2 genes (BRARE; see Introduction). When cotransfected with the control parental expression vector pSG5, RARE1-TKCAT and RARE2-TK-CAT were 4- to 6-fold all-trans RA induced by HeLa cell endogenous receptors, whereas BRARE-TK-CAT was 12-fold induced. The magnitude of the RARE1-TK-CAT and RARE2-TK-CAT induction was increased to 10- to 20-fold upon cotransfection with mRAR $\alpha 1, \beta 2$, or $\gamma 1$ and 6- to 10-fold with mRXRs (se日 Figure 1A; data not shown). Thus, RARE1 and RARE2 can confer all-trans RA inducibility on a heterologous promoter, but their differential activation by RAR and RXR appears to be lost in the context of the TK promoter.

The ability of isolated RAR and RXR to bind to CRABPII response elements in vitro was investigated by a gel shiftretardation assay using labeled oligonucleotide probes corresponding to BRARE, RARE2, RARE1, RARE2m3, RARE2m5, RARE2m6 (Figure 3), in vitro translated mRAR $\gamma$ (similar results were obtained with mRAR $\alpha$ or $\beta$; data not shown), and an antigen-tagged fusion protein, mRXRaER(F), that contains the $F$ region of the human estrogen receptor (ER) fused to the carboxy-terminal amino acid of $m R X R a$. This fusion protein contains the epitope for and can be used in supershift assays with an anti-ER(F) antibody, and it has been shown to have the same binding properties as $m R X R \alpha$ (Leid et al., 1992). At the concentrations of mRAR $\gamma$ used $(\sim 10 \mathrm{fmol}$ of receptor per assay), no detectable complex was formed with any of the response elements in the absence of $m R X R \alpha E R(F)$ (Figure 3, lanes 4, 12, and 20) or $m R \times R \alpha$ (data not shown). Likewise, in the absence of $m R A R \gamma, m R X R \alpha E R(F)$ was unable to form any detectable specific complex with the above elements (Figure 3, lanes 2, 10, and 18). However, consistent with recent reports (Yu et al., 1991; Leid et al., 1992), a strong retarded complex was observed for BRARE (Figure 3, lane 6), RARE2 (Figure 3, lanes 14 and 32), RARE1 (Figure 3, lane 22), and RARE2m3 (Figure 3, lane 35 ) in the presence of both mRARy and mRXRaER(F). In each case, the complex could be supershifted by either anti-mRARy (Ab4y; Figure 3, lanes 8, 16, 24, 33, and 36 ) or anti-ER(F) antibody (AbF3; Figure 3, lanes 7, 15, and 23) and migrated at the same position for the four probes (Figure 3, lanes 25-30,32, and 35). In the case of RARE2m5 and RARE2m6, where each core motif of RARE2 was separately mutated (Figure 3), no RAR-RXR complex could be detected (data not shown). Thus, RAR and RXR bind cooperatively on RARE2 and RARE1, and RAR-RXR heterodimers recognize RARE2 and RARE$2 \mathrm{~m} 3$ (where the degenerate motif $5^{\prime}$-TAGCC-3' has been mutated; Figure 3) with the same efficiency.

To determine the relative affinity of the RAR-RXR heterodimers for CRABPII RAREs, competition experiments were performed using RARE1, RARE2, and BRARE as labeled probes or "cold" competitors and in vitro translated $m R A R \gamma$ and $m R X R \alpha$. The relative affinity of RAR-RXR heterodimers for BRARE was approximately 6 times greater than for RARE2 and 10 times greater than for RARE1, something confirmed by competition with cold RARE1 and RARE2 (data not shown).

\section{All-Trans RA- and 9-Cis RA-Induced Transcription from the CRABPII Gene Promoter Is Medlated by} RARE1- and RARE2-Bound RAR-RXR Heterodimers To investigate whether the results of receptor binding in vitro could be correlated with transcriptional activation by heterodimers in vivo, we cotransfected mRAR $\alpha$ and mRXR $\alpha$ expression vectors with CRABPII-CATm 1 (which contains only the DR2 RARE1) and CRABPII-CATm2 (which contains only the DR1 RARE2; see Figure 1A) under ligand conditions that enabled us to differentiate between RXR and RAR activation. Results from our laboratory (M. T. Bocquel et al., unpublished data) have shown that exposure of cells to $50 \mathrm{nM}$ all-trans $\mathrm{AA}$ for $15 \mathrm{hr}$ results in RAR but not RXR activation, whereas under the same conditions $50 \mathrm{nM}$ 9-cis RA induces transcriptional activation through both RAR and RXR (see Figure 6).

P19 cells were transfected with either CRABPII-CATm1 or CRABPII-CATm2 and expression vectors encoding either mRAR $\alpha$ or $\mathrm{mRXR \alpha}$ or both. The cells were treated 24 hr later with either all-trans RA ( $50 \mathrm{nM})$, 9-cis RA (50 nM), both ligands together, or vehicle (ethanol) for an additional 12-15 hr (Figure 4 and CAT assays not shown). In the presence of mRARa alone, CRABPII-CATm1 expression was stimulated 4- to 6-fold by either all-trans RA or 9-cis RA (Figure 4, lanes 1-4), whereas a lesser stimulation was observed for CRABPII-CATm2 (Figure 4, lanes 13-16). In the presence of mRXRa, CRABPII-CATm2 was induced 15-fold by 9-cis RA (but not by all-trans RA; Figure 4, lanes 17-20), while under the same conditions CRABPICATm1 was stimulated only 4-fold (Figure 4, lanes 5-8). However, when RAR $\alpha$ and RXR $\alpha$ were cotransfected, a clear increase in all-trans RA and 9-cis RA inducibility was detected for both CRABPII-CATm1 and CRABPIICATm2 (Figure 4, lanes 9-12 and 21-24, respectively). This increase was particularly striking in the case of CRABPIICATm2, for which there was a marked induction by all-trans RA that was not observed with either of the two receptors alone (compare lanes 14, 18, and 22 in Figure 4). These data strongly suggest that RAR-RXR heterodimers 

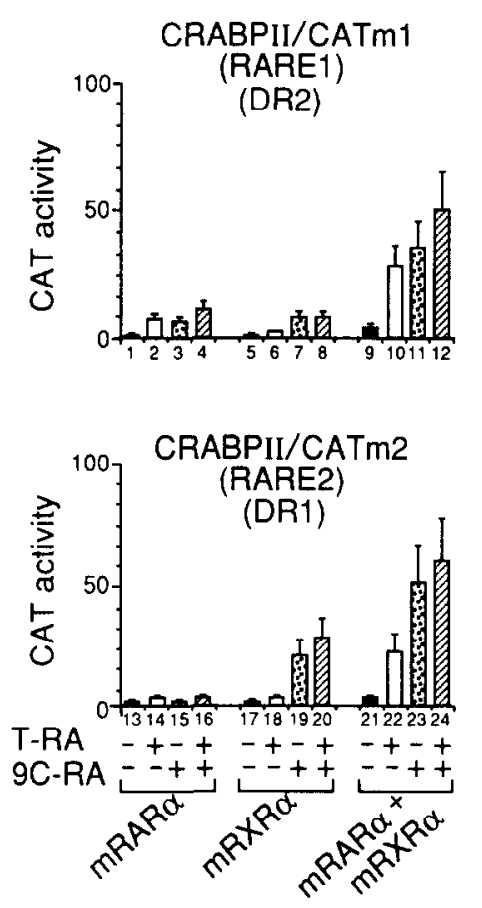

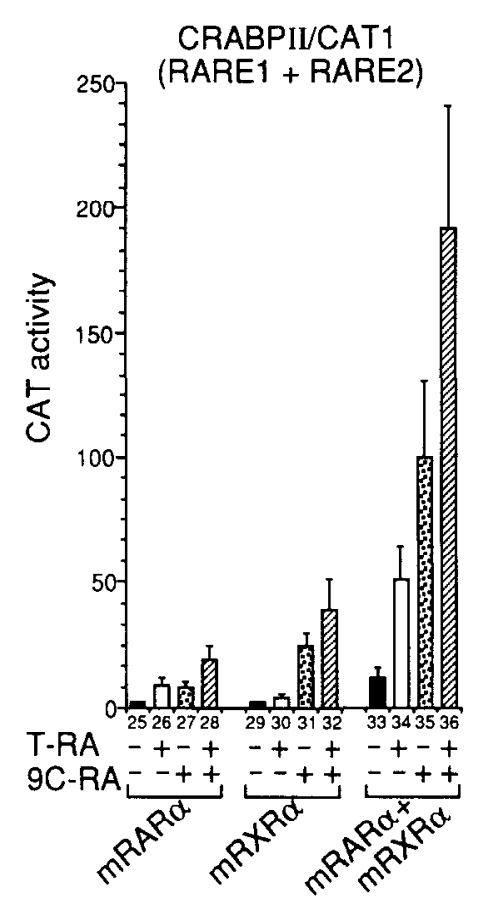

Figure 4. Cotransfection of mRAR $\alpha$ and mRXRa. Enhance All-Trans RA- and 9-Cis RAInduced Response of CRABPII-CATm1, CRABPII-CATm2, and CRABPII-CAT1

P19 EC cells were transfected with $10 \mu \mathrm{g}$ of reporter plasmids CAABPII-CATm1, CRABPIICATm2, or CRABPII-CAT1 and $500 \mathrm{ng}$ of mRARa or mAXRa or both (as indicated). The transcriptional response of these reporter genes after a 12-15 hr treatment (as indicated) with either all-trans RA (T-RA) ( $50 \mathrm{nM})$, 9-cis RA (9C-RA) (50 nM), or both ligands was determined by measurement of the CAT activity that is given in arbitrary units. bind to and activate transcription in vivo from either the DR2 RARE1 or the DR1 RARE2 and also that each partner within the heterodimeric complex is able to activate transcription independently.

To support this hypothesis further, we made use of C-terminally truncated mRXR $\alpha$ and $\mathrm{mRAR} \alpha$ mutants that have lost their ligand-dependent transcription activation function but still heterodimerize and bind RARE1 and RARE2 In vitro as efficiently as their wild-type counterparts (M. S. et al., unpublished data). These mutants abolished liganddependent transactivation by their wild-type counterparts when transfected in a 10-fold excess, most likely by competition in a molar ratio, and are therefore referred to as dominant-negative (dn) receptors hereafter. Assuming that RARE1 and RARE2 mediate transactivation by RARRXR heterodimers, it was therefore expected that in the presence of $50 \mathrm{nM}$ all-trans RA and/or 9-cis RA, RARRXRdn heterodimers would stimulate transcription with the same efficiency as RAR-RXR heterodimers in the presence of only $50 \mathrm{nM}$ all-trans RA. On the other hand, activation by RXR-RARdn in the presence of $50 \mathrm{nM}$ 9-cis RA would only correspond to the additional activation that is seen when wild-type RAR-RXR heterodimers are induced by 9 -cis RA instead of by all-trans RA (see Figure 5 for a schematic representation).

The above prediction was first tested in the case of CRABPII-CATm1, which contains the DR2 RARE1 (Figure $6 A$ ). When compared with transfection of mRAR $\alpha$ alone (Figure 6A, lanes 1-3), a cotransfection of $100 \mathrm{ng}$ of mRAR $\alpha$ and $100 \mathrm{ng}$ of mRXRdn in P19 cells resulted in an increased all-trans RA-dependent induction that was similar to that observed with cotransfection of wild-type mRARa and mRXRa (compare lanes 10-12 with lanes $7-9$ in Figure $6 A$; note that only $100 \mathrm{ng}$ of RAR and RXR expression vectors was used in the experiments shown in Figure 6, instead of $500 \mathrm{ng}$ as in Figure 4). Moreover, cotransfection of $m R X R \alpha$ and mRARdn resulted in a 9-cis RA-specific activation (Figure 6A, lanes 13-15), which corresponded to the difference in the activations achieved with cotransfected wild-type mRAR $\alpha$ and $\mathrm{mRXR} \alpha$ in the presence of 9-cis RA or all-trans RA (Figure 6A, lanes 7-9). Cotransfection of a large excess of either mRXRdn (Figure 6A, lanes 16-18) or mRARdn (Figure 6A, lanes 19-21), together with $m R X R \alpha$ and mRAR $\alpha$, had the effect expected for transactivation by RAR-RXR heterodimers (see Figure 5). Within the heterodimers, mRAR $\alpha$ was more efficient than mRXR $\alpha$ at stimulating transcription from the DR2 RARE1 in CRABPII-CATm1.

Similar transfections were performed in $\mathrm{P} 19$ cells with CRABPII-CATm2 that contains the DR1 RARE2 (Figure $6 B)$. Cotransfection of mRAR $\alpha$ with mRXRdn increased markedly all-trans RA- and 9-cis RA-dependent mRARa activity (Figure 6B, lanes 11 and 12) to the same extent as cotransfection of mRAR $\alpha$ and wild-type $\mathrm{mRXR} \alpha$ (Figure $6 \mathrm{~B}$, lanes 7 and 8 ). The cotransfection of $\mathrm{mRXR} \alpha$ with mRARdn resulted in a 9-cis RA-dependent mRXR $\alpha$ activity (Figure 6B, lanes 13-15), which corresponded to the difference between the all-trans RA-and 9-cis RA-dependent activities when mRAR $\alpha$ and $m R X R \alpha$ were cotransfected (Figure 6B, lanes 7-9). However, the 9-cis RAdependent activity of mRXRa-mRARdn heterodimers was very similar to that observed when $m R X R a$ alone was transfected (compare lanes 13-15 with lanes 4-6 in Figure $6 \mathrm{~B})$, which suggests that $\mathrm{mRXR \alpha}$ may act by binding RARE2 either as a heterodimer with mRAR $\alpha$ or as a homodimer. It is noteworthy that, in contrast with observations of the DR2 RARE1 (CRABPII-CATm1; Figure 6A, lanes $7-9$ ), the RXR component of the heterodimer was as effi- 
(A)

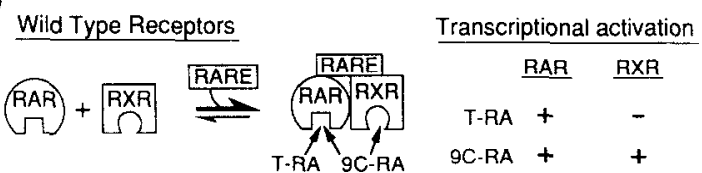

(B)

Activation-minus RXR mutant (RXRdn)

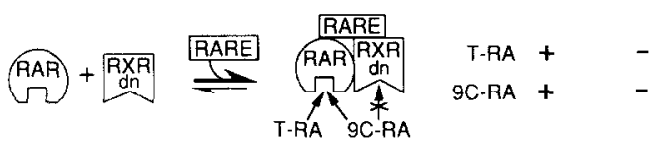

(C) Activation-minus RAR mutant (RARdn)

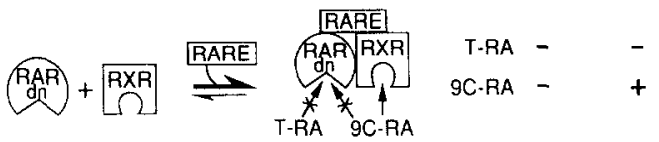

Figure 5. Schematic Representation of All-Trans RA- and 9-Cis RADependent Transcriptional Activation by Wild-Type and Mutant RARRXR Heterodimers

RARdn and RXRdn correspond to dominant-negative mutants of RAR and RXR that can bind to RAREs but have lost their ligand-dependent activation function. Arrows pointing from either all-trans RA (T-RA) or 9-cis RA (9C-RA) indicate that the ligand, at $50 \mathrm{nM}$ concentration, is able to activate the corresponding receptor in P19 cells, whereas crossed-out arrows indicate that the receptor cannot be activated.

cient as its RAR partner at activating transcription though the DR1 RARE2 (compare all-trans RA- and 9-cis RAdependent activities in lanes 7-9 and 16-21 of Figures 6A and 6B). Note also that cotransfection of a large excess of mRXRdn resulted in a 2- to 3-fold RA-independent activation of transcription (especially in the case of RARE2; see Figures $6 \mathrm{~A}$ and $6 \mathrm{~B}$, lanes 16 ), which suggests that $a$ ligand-independent transcriptional activation function may be present in mRXRa.

We conclude from all of the above results that RAR and RXR bind as heterodimers to either the DR2 RARE1 or DR1 RARE2, from which they can activate transcription independently. To investigate whether heterodimers bound to RARE1 and RARE2 could synergize within the CRABPII promoter, CRABPII-CAT1 was cotransfected with mRAR $\alpha$, mRXR $\alpha$, or the two receptors together, and the resulting all-trans RA- and/or 9-cis RA-dependent transcriptional activation was compared with that achieved with either CRABPII-CATm1 (containing RARE1 only) or CRABPII-CATm2 (containing RARE2 only) (see Figure 4). No strong increase above the activation expected from additivity was observed ( 2 -fold in the presence of both all-trans RA and 9-cis RA), indicating that the heterodimers bound to RARE1 and RARE2 are only weakly synergizing within the CRABPII promoter under these P19 cell transfection conditions.

mCRABPII mRNA Levels Are Increased in P19 Cells by Elther All-Trans RA or 9-Cis RA, but 9-Cis RA Is More Efficient Than All-Trans RA

To determine whether the above transfection observations could be correlated with in vivo effects of all-trans RA and 9-cis RA on the activity of P19 cell endogenous RARs and

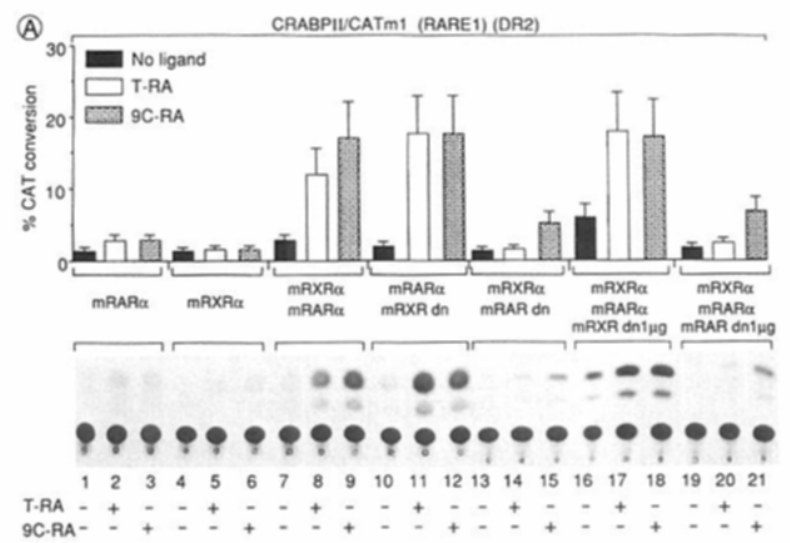

(B)

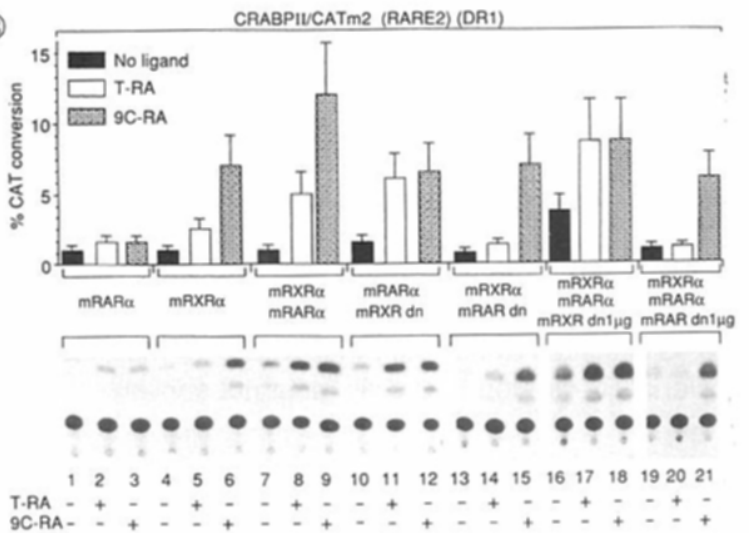

Figure 6. Cotransfected RARdn and RXRdn Stimulate Activation of Transcription Mediated by RAR and RXR Wild Type on CRABPIICATm1 (RARE1) and CRABPII-CATm2 (RARE2)

P19 EC cells were cotransfected as indicated with $10 \mu \mathrm{g}$ of CRABPICATm1 (A) or $10 \mu \mathrm{g}$ of CRABPII-CATm2 (B) and mRAR $\alpha(100 \mathrm{ng})$, mRXRa (100 ng), mRARadn (100 $\mathrm{ng}$ or $1 \mu \mathrm{g}$ as indicaled), and mRXRadn (100 ng or $1 \mu \mathrm{g}$ as indicated). Cells were treated with either all-trans RA (T-RA) (50 nM) or 9-cis RA (9C-RA) $(50 \mathrm{nM})$ for $12-15 \mathrm{hr}$, and CAT activity was determined. Representative CAT assays and graphs corresponding to average values from several independent experiments are shown.

RXRs, mCRABPII expression was analyzed by Northern blotting of RNAs prepared from all-trans RA- and/or 9-cis RA-treated cells, using a ${ }^{32} \mathrm{P}$-labeled mCRAPBII CDNA probe (Figure 7). After a $15 \mathrm{hr}$ all-trans RA or 9-cis RA treatment $(50 \mathrm{nM}), \mathrm{mCRABPII}$ transcripts were increased $\sim 20$-fold by all-trans RA, $\sim 60$-fold by 9 -cis RA, and $\sim 300$ fold when the two ligands were added together (Figure 7). Under these suboptimal all-trans RA and 9-cis RA concentrations, some variability was observed in the extent of these increases, particularly in the further stimulation brought about by the addition of both ligands, but 9-cis RA was consistently 3- to 8-fold more efficient than all-trans RA in repeated experiments. In marked contrast, mAARß2 mRNA levels were identically increased in the same cells by either all-trans RA or 9-cis RA treatment, and no significant increase was observed when the two ligands were added together. At least part of the increase in RARB2 and CRABPII mRNAs was due to increased rates of transcrip- 


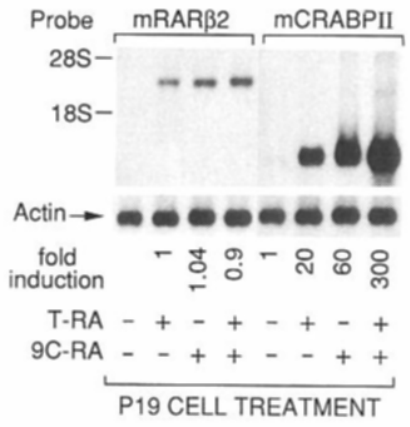

Figure 7. Inducibility of mRARB2 and mCRABPII mRNA in P19 EC Cells Treated with All-Trans RA and/or 9-Cis RA

Shown are autoradiograms of Northern blots of poly $(A)^{+}$RNA $(2 \mu \mathrm{g}$ per lane) obtained from P19 EC cells grown in the presence of all-trans RA (T-RA) (50 nM), 9-cis RA (9C-RA) (50 nM), or both ligands (50 nM) for $15 \mathrm{hr}$ and hybridized with randomly primed ${ }^{32} \mathrm{P}$-labeled CDNA probes specific for mRAR 22 and mCRABPII. Actin mRNA control is also shown, and the fold inductions are indicated. Note that in the case of mRARß2 where no signal could be detected in the absence of RA treatment, the induction achieved with all-trans RA treatment alone was taken as 1.

tion as indicated by nuclear run-on assays performed with nuclei of RA-treated P19 cells (data not shown).

\section{Discussion}

\section{The Recognition of DR Elements by RAR-RXR Heterodimers Is Not Specified by a Unique Spacing of the Repeated Motifs}

Our present data clearly establish that RARE1 and RARE2 are located in the $5^{\prime}$ flanking region of the mCRABPII gene. Both RAREs correspond to the direct repetition of a sequence identical or closely related to the core motif $5^{\prime}-\mathrm{PuG}(\mathrm{G} / \mathrm{T}) \mathrm{TCA}-3^{\prime}$, which is found in a number of natural RA-responsive promoters (see Introduction). In RARE1 these two motifs are separated by $2 \mathrm{bp}$, whereas they are spaced by 1 bp in RARE2. In this respect, RARE 1 is similar to the CRBPI RARE (Smith et al., 1991), whereas RARE2 is related to the rat CRBPII putative RARE, in which the spacings between several core motifs are 1 bp (Mangelsdorf et al., 1991), as well as to response elements that have been found in the 5 ' flanking regions of a number of other putative RA-responsive genes (Hamada et al., 1989; Lucas et al., 1991; Rottman et al., 1991). Both RARE1 and RARE2 are different from the RAREs found in other characterized natural RA target genes, i.e., the human and mouse RAR $\beta 2$ and RARE $\alpha 2$ genes (and possibly the human ADH3 gene; Duester et al., 1991) and the mouse laminin B1 gene, in which the directly repeated core motifs are spaced by 5 bp and 4 bp, respectively (see Introduction).

The results of binding and transactivation studies, mainly performed with synthetic response elements and chimeric RA-responsive promoters, have suggested that the spacing between the core motifs may correspond to a discriminating recognition code for various members of the nuclear receptor superfamily, in which directly repeated motifs separated by 5 bp (DR5), 4 bp (DR4), 3 bp (DR3), and $1 \mathrm{bp}$ (DR1) correspond to binding sites for RARs, thyroid hormone receptors, vitamin $D_{3}$ receptors, and RXRs, respectively (Umesono et al., 1991; Kliewer et al., 1992a; see also Näär et al., 1991). In addition, it has been reported that a DR1 element binds RXR-COUP-TF (ear3) heterodimers and that this heterodimeric binding results in the suppression of transactivation by RXR(Kadowaki, 1992; Kliewer et al., 1992a). However, additional systematic binding and transactivation studies have indicated that RARs can bind to and activate transcription from DR5 and DR2 elements and, with a lesser efficiency, from DR4 and DR3 elements (Mader et al., 1992). These latter observations, together with those made with RAREs of promoters of natural target genes, including the DR2 element of the mouse CRBPI gene (Smith et al., 1991) and the present CRABPII elements, indicate that if a recognition code exists, it must be highly degenerate. In fact, recent in vitro studies have shown that under the limiting receptor concentrations that are likely to exist in vivo, RAR-RXR heterodimers bind much more efficiently to the various DR1 to DR5 elements than to the corresponding homodimers (Yu et al., 1991; Kliewer et al., 1992b; Leid et al., 1992; Zhang et al., 1992; B. D., M. S., P. L., M. L., and P. C., unpublished data). Since DR elements are asymmetrical, it is possible that the above degeneracy reflects at least in part the nonequivalence of the two core motits of a given DR for the binding of RAR-RXR heterodimers.

\section{Differential and Independent Transactivation by RAR and RXR Members of Heterodimers Bound to Different DR Elements}

Our present cotransfection studies with CRABPII promoter constructs containing either RARE1 or RARE2 and wild-type and dominant-negative RAR and RXR demonstrate unambiguously that RAR-RXR heterodimers can bind to and transactivate from a single natural DR2 or DR1 RARE more efficiently than either of the corresponding homodimers, thus establishing that RAR-RXR heterodimers can control a bona fide RA-responsive promoter in vivo via DR2 and DR1 elements. Moreover, each member of the heterodimeric complex appears to be able to activate transcription independently. Interestingly, the respective contribution of the two partners of RAR-RXR heterodimers to transcriptional activation appears to be dependent on the nature of the RARE. The contribution of the RAR transactivation function(s) is clearly preponderant in the case of the DR2 RARE1, whereas the RAR and RXR transactivation functions appear to contribute equally to stimulation of transcription in the case of the DR1 RARE2. These variations in the transactivation properties may reflect modifications in the ligand-binding domain and/or the activation domain of RAR and RXR members of heterodimeric complexes bound to different RARE types. RAR and RXR dimerization domains are indeed localized within the same E region that also contains the ligand-binding domain and an activation function (see Leid et al., 1992; Nagpal et al., 1992). In this respect, we note that RAR was found to be almost exclusively responsible for activation of transcription when similar cotransfection experiments were performed in P19 cells with RXRdn mutants and the RARB2 
promoter that contains a DR5 element (M. S. et al., unpublished data). That the contribution of RAR and RXR to transcriptional activation may also be promoter context dependent is suggested by the results obtained with RARE1-TK-CAT and RARE2-TK-CAT (Figure 1A). This may possibly reflect differences in synergism between RAR and RXR and additional promoter-specific transactivators.

It is noteworthy that RXR transfected on its own could bring about a several-fold stimulation of transcription mediated by RARE2 (DR1) but not by RARE1 (DR2) (Figures 4 and 6). This observation suggests that, while RAR-RXR heterodimers bind more efficiently than either RXR or RAR homodimers to RARE2 and RARE1 (no RXR homodimer binding to either RARE1 or RARE2 was seen in vitro at low RXR concentrations; Figure 3), RXR homodimers may nevertheless bind to RARE2 at high RXR concentrations in vivo. Alternatively, $R X R$ may be able to bind to the $D R 1$ RARE2 (but not to the DR2 RARE1) as a heterodimer with an yet unidentified partner, which, however, is unlikely to be COUP-TF, since RXR appears to be inactive in RXRCOUP-TF heterodimers (Kliewer et al., 1992b; B. D., unpublished data)

\section{Differential Response of the CRABPII and RARB2 Genes to RAR and RXR in P19 Cells and \\ Combinatorial Effects in the RA Signaling Pathway}

The present dissection of the CRABPII promoter response to RA provides interesting insights into the question of how the RA signal can generate pleiotropic effects during embryogenesis and in homeostasis. Our data clearly suggest that the response of a given promoter is potentially dependent on the DR characteristics of the RARE, the relative RAR and RXR concentrations, and the intracellular levels of all-trans RA and 9-cis RA. In addition, studies from our laboratory (Nagpal et al., 1992) have shown that each of the three RARs and of the three RXRs possesses one transcription activation function and one transcription modulating function that are located in the C-terminal $E$ region and the $\mathrm{N}$-terminal $\mathrm{A} / \mathrm{B}$ regions, respectively, and that exhibit different promoter context specificities. Diversity in RA responses could obviously result from specific combinatorial assortments of all of the above parameters.

That our transfection results do not chiefly correspond to artifacts generated by the production of high levels of RAR and/or RXR in transfected P19 cells is demonstrated by the characteristics of activated expression of the endogenous CRABPII gene when P19 cells are exposed to either all-trans RA or 9-cis RA under conditions (ligand concentrations of $50 \mathrm{nM}$ ) where all-trans RA induces only RAR activity and 9-cis RA induces both RAR and RXR activity (Figure 6). CRABPIl gene expression was consistently induced to a higher level by 9-cis RA than by all-trans RA (Figure 7 ). In marked contrast, in the same cells the expression of the endogenous RARB2 gene was similarly activated by either all-trans RA or 9-cis RA, thus providing clear-cut evidence that both RAR and RXR activation functions are implicated in activation of expression of the CRABPII gene, whereas only the RAR transactivation function(s) is involved in the induction of the RARB2 pro- moter. This differential response of CRABPII and RARB2 promoters represents a clear example of generation of RA response diversity due to combinatorial effects, as discussed above. However, we did not find any major differences in the ability of the different RAR and RXR types ( $\alpha$, $\beta$, or $\gamma$ ) to transactivate the CRABPII promoter in transfected P19 cells. Such differences may be masked by the nonphysiological high concentration of receptors that is generated in transfected cells. Gene disruption studies are in progress in both P19 EC cells and in the mouse to characterize the RAR and RXR types that may possibly be specifically responsible for activation of CRABPII gene expression.

The function of CRABPIl during embryogenesis and in the adult is unknown, although the distribution of its transcripts is clearly distinct from that of CRABPI (Maden et al., 1988, 1989; Dollé et al., 1989, 1990; Maden, 1991; Ruberte et al., 1991b, 1992; Tabin, 1991). It has been speculated that, even though they may not be directly involved in mediating the RA signal (Breitman et al., 1981; Douer and Koeffler, 1982; Libby and Bertran, 1982), these RA-binding proteins could finely tune the actual concentration of free RA in the cell (Robertson, 1987; Maden et al., 1988; Smith et al., 1989; Balling, 1991; Boylan and Gudas, 1991; Ruberte et al., 1991b). That these proteins play an important function in the RA signaling pathway is indicated by the lethal effect of the disruption of the CRABPI gene early in mouse embryogenesis (T. Lufkin et al., unpublished data). In this respect, the observation that CRABPII gene expression is induced by both all-trans RA and 9 -cis RA suggests that CRABPII may play an important role in the cellular interpretation of the RA signal. 9-Cis RA has indeed been found in a number of tissues (Heyman et al., 1992). It is presently unknown whether CRABPI and/or CRABPII binds 9-cis RA. In any event, an induction of CRABPII expression by all-trans RA would probably result both in a decrease of free all-trans RA and in a reduction in the production of 9-cis RA that appears to be derived from all-trans RA (Heyman et al., 1992; Levin et al., 1992). We note in this respect that the CRABPII mRNA levels are markedly increased in P19 cells at $50 \mathrm{nM}$ all-trans RA, which corresponds to the total concentration of all-trans RA in the chicken limb (Smith et al., 1989; Tabin, 1991).

Experimental Procedures

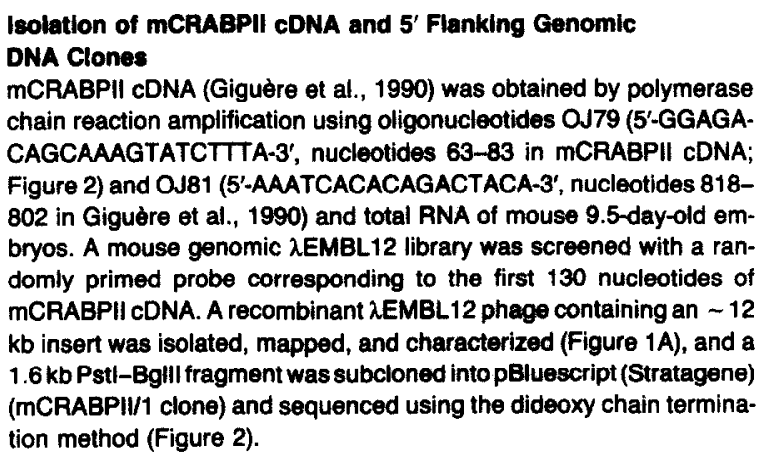

Primer Extension Mapping of the mCAABPII Transcriptional Start Site

The transcriptional start site was mapped by primer extension using 
a synthetic oligonucleotide complementary to nucleotides +103 to +64 in the CRABPII gene sequence (underlined in Figure 2). The ${ }^{32} \mathrm{P}-5^{\prime}$ end-labeled oligonucleotide was annealed at $30^{\circ} \mathrm{C}$ with $10 \mu \mathrm{g}$ of poly(A) RNA prepared from all-trans RA treated $\left(10^{-6} \mathrm{M}\right)$ and untreated P19 EC cells and extended using avian myeloblastosis virus reverse transcriptase. Primer extension products, along with DNA sequencing reactions on CRABPII/1 using the above oligonucleotide as a primer, were electrophoresed on 6\% urea-polyacrylamide gels and autoradiographed (data not shown).

\section{Construction of Promoter-CAT Reporter Genes}

A DNA fragment extending in the $5^{\prime}$ direction from the Bglll site (+118) to the Bglll site located at approximately $-2.5 \mathrm{~kb}$ was subcloned into the Bglll site of the CAT reporter plasmid pBLCAT3 ${ }^{+}$(Luckow and Schütz, 1987), giving CRABPII-CAT1 (Figure 1A). To produce CRABPII-CAT2, 3, and 4 (Figure 1A), CRABPII-CAT1 was partially digested with Pstl and Xbal and religated on itself. CRABPII-CAT5 and CRABPII-CAT6 were produced by digestion of CRABPII-CAT2 with $X$ bal and Xhol, respectively, and religation. The CRABPII-CATm1, $\mathrm{m2}$, and $\mathrm{m} 3$ mulants were obtained by double polymerase chain reaction amplification reactions as previously described (Ho et al., 1989). The oligonucleotides used were as follows: for CRABPII-CATm1, 5'-GGATTGCCTGACTCGAGTGACACTGTCTGG-3', 5'-GGCAGCCCCGCATTGGGACGCTGGGGACTT-3', 5'-CCCTCAGTCTTCCCGGGGCTATCCCCGTAG-3', and 5'-AAGTCCCCAGCGTCCCAATGCGGGGCTGCC-3', generating a Xmal-Xhol fragment containing the mutated bases; for CRABPII-CATm2, 5'-CAGCAAGCCGCGGGGTGGGGGTGG-3', 5'-GCCTGCAGGGCGAACACAGGT-3', 5'-GAGCCCCCGGCTCGACAATCACTTGACACG-3', and 5'-CGTGTCAAGTGATTGTCGAGCCGGGGGCTC-3', generating a mutated Sacll-Pstl fragment. These two fragments were then independently inserted into CRABPII-CAT1. For CRABPII-CATm3, we used the same first two oligonucleotides as for CRABPII-CATm2 and 5'-CCCCCGGCTCGATTCTAGAAGGGCAG-3' and 5'-CTGCCCTTCTAGAATCGAGCCGGGGG-3'; the generated Pstl-Sacll fragment was inserted into CRABPIICATm2. CRABPII-CATm4 was generated by insertion of the two mutated fragments Xhol-Xmal and Sacll-Pstl into CRABPII-CAT1. RARE1-TK-CAT, RARE2-TK-CAT, and BRARE-TK-CAT were constructed by inserting CRABPI RARE1, RARE2, or mRARB2 RARE (BRARE) into the Hindlll-Xbal sites of pBLCAT2 ${ }^{+}$(Luckow and Schütz, 1987), as indicated in Figure 1A.

\section{Cell Transfection and CAT Assay}

P19 EC and HeLa cells were cultured in Dulbecco's modified Eagle's medium containing $5 \%$ charcoal-treated fetal calf serum. Cells were transfected 4-6 $\mathrm{hr}$ after plating using the calcium phosphate procedure as described previously (Kumar et al., 1986) with $10 \mu \mathrm{g}$ of the CAT reporter plasmids (as described in the figure legends), along with vectors expressing mRAR $\alpha 1, \beta 2$, or $\gamma 1$ (Zelent et al., 1989) or mRXR $\alpha, \beta$, or $\gamma$ (Leid et al., 1992), mRARadn or mRXRadn (M. S. et al., unpublished data) or the parental expression vector pSG5 (Green et al., 1988 ), and $2 \mu g$ of $\beta$-galactosidase expression vector $p C H 110$ (Pharmacia), which was used as an internal control to normalize for variations in transfection efficiency. The total amount of DNA in each transfection was standardized to $15 \mu \mathrm{g}$ using carrier DNA (Bluescript). The medium was changed after 15-20 hr, and the appropriate ligands (all-trans RA or 9-cis RA) dissolved in ethanol were added to a final concentration of $1 \mu \mathrm{M}$ or $50 \mathrm{nM}$ (as described in the figure legends). After an additional period of either 12 or $24 \mathrm{hr}$, the cells were harvested and cellular extracts were prepared as described previously (Petkovitch et al., 1987). Cell extracts containing $50 \mathrm{U}$ of $\beta$-galactosidase activity were used for CAT assays. The CAT activity was quantified by scintillation counting (see the figure legends).

Gel Retardation Assays

Gel shift-retardation experiments, including antibody supershift assays, were as previously described (Nicholson et al., 1990; Smith et al., 1991). The anti-mRAR $\gamma$ antibody has been described (Rochette-Egly et al., 1991), and the anti-human $E R$ region $F$ antibody (AbF3) was a gift from D. Metzger. Receptors were synthesized by transcription-translation in vitro using reticulocyte rabbit lysate in the presence and absence of [35]methionine. Radiolabeled proteins were analyzed by SDS-polyacrylamide gel electrophoresis, and the data were used to normalize the amount of unlabeled receptor (translated in parallel) added to gel retardation assays. The amount of receptor used per assay was approximately $10 \mathrm{fmol}$.

RNA Isolation and Northern Blotting

Poly(A) ${ }^{+}$RNA from P19 EC cells treated for $15 \mathrm{hr}$ with $50 \mathrm{nM}$ all-trans RA, $50 \mathrm{nM}$ 9-cis RA, or both ligands ( $50 \mathrm{nM}$ each) was isolated as described (Leroy et al., 1991b). RNA samples were then separated on $2.2 \mathrm{M}$ formaldehyde, $1 \%$ agarose gel, transferred to nitrocellulose membrane in $20 \times$ SSC, fixed by $2 \mathrm{hr}$ baking at $80^{\circ} \mathrm{C}$, and hybridized by using randomly primed ${ }^{32}$ P-labeled probes corresponding to the complete CDNA of mCRABPII or to a CDNA probe specific for mRARB2 (Zelent et al., 1991) in $5 \times$ Denhardt's solution, $5 \times$ SSPE, 0.1\% SDS, $100 \mu \mathrm{g} / \mathrm{ml}$ salmon sperm DNA at $65^{\circ} \mathrm{C}$. The membranes were then washed three times with $2 \times \mathrm{SSC}, 0.1 \%$ SDS at $60^{\circ} \mathrm{C}$. Autoradiography was from 1 to 3 days at $-80^{\circ} \mathrm{C}$ with an intensitying screen.

\section{Acknowledgments}

We are grateful to Dr. J. Grippo and A. Levin for a generous gift of 9-cis-RA and useful discussions. We thank M. P. Gaub, C. RochetteEgly, Y. Lutz, D. Metzger, and S. Ali for a generous gift of antibodies; C. Reibel, R. Lyons, and J.M. Garnier for technical help; F. Ruffenach and A. Staub for oligonucleotide synthesis; the cell culture staff for providing cells; P. Kastner, H. Nakshatri, M. T. Bocquel, A. Krust, C. Mendelsohn, and other members of the receptor group for plasmids, advice, and discussions; and P. Kastner, H. Nakshatri, and H. Gronemeyer for critical reading of the manuscript. We are grateful to $C$. Werlé for preparing the figures and to the secretarial staff for their help in typing the manuscript. M. S. is supported by a long-term European Molecular Biology Organization fellowship, and M. L. is supported by a fellowship from the Leukemia Society of America. This work was also supported by funds from the Institut National de la Santé et de la Fecherche Médicale, the Centre National de la Recherche Scientifique, the Centre Hospitaller Universitaire Régional, the Association pour la Recherche sur le Cancer, the Fondation pour la Recherche Médicale, and the Human Science Frontier Program.

The costs of publication of this article were defrayed in part by the payment of page charges. This article must therefore be hereby marked "edvertisement" in accordance with 18 USC Section 1734 solely to indicate this fact.

Received May 9, 1992; revised July 1, 1992.

\section{References}

Angel, P., Imagawa, M., Chiu, R., Stein, B., Imbra, R. J., Rahmsdorf, H. J., Jonat, C., Herrlich, P., and Karin, M. (1987). Phorbol esterinducible genes contain a common cis element recognized by a TPAmodulated trans-acting enhancer. Cell 49, 729-739.

Aström, A., Tavakkol, A., Petersson, U., Cromie, M., Elder, J. T., and Voorhees, J. J. (1991). Molecular cloning of two human cellular retinoic acid-binding proteins CRABP. J. Biol. Chem. 266, 17662-17666.

Bailey, J. S., and Siu, C.-H. (1988). Purification and partial characterization of a novel binding protein for retinoic acid from neonatal rat. J. Biol. Chem. 263, 9326-9332.

Balling, R. (1991). CRABP and the teratogenic effects of retinoids. Trends Genet. 7, 35-36.

Beato, M. (1989). Gene regulation by steroid hormones. Cell 56, 335344.

Blomhoff, R., Green, M. H., Green, J. B., Berg, T., and Norum, K. R. (1991). Vitamin A metabolism: new perspectives on absorption, transport and storage. Physiol. Rev. 71, 952-982.

Blumberg, B., Mangelsdorf, D. J., Dyck, J. A., Bittner, D. A., Evans, R. M., and De Robertis, E. M. (1992). Multiple retinoid-responsive receptors in a single cell: families of retinoid " $X$ " recoptors and retinoic acid receptors in the Xenopus egg. Proc. Natl. Acad. Sci. USA 89, 2321-2325.

Boylan, J. F., and Gudas, L. J. (1991). Overexpression of the cellular retinoic acid binding protein-l (CRABP-1) results in a reduction in differentiation-specific gene expression in F9 teratocarcinoma cells. J. Cell Biol. 112, 965-979. 
Breitman, T. R., Collins, S. J., and Keene, B. R. (1981). Terminal differentiation of human promyelocytic leukemia cells in primary culture in response to retinoic acids. Bload 57, 1000-1004.

Briggs, M. R., Kadonaga, I. T., Bell, S. P., and Tjian, R. (1986). Purification and biochemical characterization of the promoter-specific transcription factor Sp1. Sclence 234, 47-52.

Brockes, J. P. (1989). Retinoids, homeobox genes, and limb morphogenesis. Neuron 2, 1285-1294.

Brockes, J. P. (1990). Reading the retinoid signals. Nature 345, 766768.

Bugge, T. H., Pohl, J., Lonnoy, O., and Stunnenberg, H. G. (1992). RXRa, a promiscuous partner of retinoic acid and thyroid hormone receptors. EMBO J. 11, 1409-1418.

Chambon, P., Zelent, A., Petkovich, M., Mendelsohn, C., Leroy, P., Krust, A., Kastner, P., and Brand, N. (1991). The family of retinoic acid nuclear receptors. In Retinoids: 10 Years On, J.-H. Saurat, ed. (Basel: S. Karger), pp. 10-27.

Chodosh, L. A., Olesen, J., Hahn, S., Baldwin, A. S., Guarente, L., and Sharp, P. A. (1988). A yeast and a human CCAAT-binding protein have heterologous subunits that are functionally interchangeable. Cell 53 , 25-35

Chytil, F., and Stump, D. G. (1991). Cellular retinoic acid- and retinolbinding proteins. In Retinoids: 10 Years On, J.-H. Saurat, ed. (Basel: S. Karger), pp. $38-45$.

Corden, J., Wasylyk, B., Buchwalder, A., Sassone-Corsi, P., Kedinger. C., and Chambon, P. (1980). Expression of cloned genes in new environment: promoter sequences of eukaryotic protein-coding genes. Science 209, 1406-1414.

de Luca, L. M. (1991). Retinoids and their receptors in differentiation, embryogenesis, and neoplasia. FASEB J. 5, 2924-2933.

Demmer, L. A., Birkenmeier, E. H., Sweetser, D. A., Levin, M. S., Zollman, S., Sparkes, R. S., Mohandas, T., Lusis, A. J., and Gordon, J. (1987). The cellular retinol binding protein II gene: sequence analysis of the rat gene, chromosomal localization in mice and humans, and documentation of its close linkage to the cellular retinol binding protein gene. J. Biol. Chem. 262, 2458-2467.

de The, H., Vivanco-Ruiz, M., Tiollais, P., Stunnenberg, H., and Dejean, A. (1990). Identification of a retinoic acid responsive element in the retinoic acid receptor $\beta$ gene. Nature 343, 177-180.

Didierjean, L., Durand, B., and Saurat, J.-H. (1991). Cellular retinoic acid-binding protein type 2 mRNA is overexpressed in human psoriatic skin as shown by in situ hybridization. Biochem. Biophys. Res. Commun. 180, 204-208.

Dollé, P., Ruberte, E., Kastner, P., Petkovich, M., Stoner, C. M., Gudas, L. J., and Chambon, P. (1989). Differential expression of genes encoding $\alpha, \beta$ and $\gamma$ retinoic acid receptors and CRABP in the developing limbs of the mouse. Nature 342, 702-705.

Dollé, P., Ruberte, E., Leroy, P., Morriss-Kay, G., and Chambon, P. (1990). Retinoic acid receptors and cellular retinoid binding proteins. I. A systematic study of their differential pattern of transcription during mouse organogenesis. Development 110, 1133-1151.

Douer, D., and Koeffler, H. P. (1982). Retinoic acid enhancer colonystimulating factor induces clonal growth of normal human myeloid progenitor cells in vitro. Exp. Cell Res. 138, 143-198.

Duester, G., Shean, M. L., McBride, M. S., and Stewart, M. J. (1991) Retinoic acid response element in the human alcohol dehydrogenase gene ADH3: implications for regulation of retinoic acid synthesis. Mol. Cell. Biol. 11, 1638-1646.

Elder, J. T., Aström, A., Petersson, U., Tavokkol, A., Griffiths, C. E. M. Krust, A., Kastner, P., Chambon, P., and Voorhees, J. J. (1992). Differential regulation of retinoic acid receptors and binding proteins in human skin. J. Invest. Dermatol. 98, 673-679.

Evarns, R. M. (1988). The steroid and thyroid hormone receplor superfamily. Science 240, 889-895.

Giguère, V., Lyn, S., Yip, P., Siu, C.-H., and Amin, S. (1990). Molecular cloning of $C D N A$ encoding a second cellular retinoic acid-binding protein. Proc. Natt. Acad. Sci. USA 87, 6233-6237.

Green, S., and Chambon, P. (1988). Nuclear receptors enhance our understanding of transcription regulation. Trends Genet. 4, 309-314
Green, S., Issemann, I., and Scheer, E. (1988). A versatile in vivo and in vitro eukaryotic expression vector for protein engineering. Nucl. Acids Res. 16, 369

Hamada, K., Gleason, S. L., Levi, B.-Z., Hirschfeld, S., Appella, E., and Ozato, K. (1989). H-2RIIBP, a member of the nuclear hormone receptor superfamily that binds to both the regulatory element of major histocompatibility class I genes and the estrogen response element. Proc. Natl. Acad. Sci. USA 86, 8289-8293.

Heyman, R. A., Mangelsdorf, D. J., Dyck, J. A., Stein, R. B., Eichele, G., Evans, R. M., and Thaller, C. (1992). 9-cis retinoic acid is a high affinity ligand for the retinoid $X$ receptor. Cell 68, 397-406.

Ho, S. N., Hunt, H. D., Horton, R. M., Pullen, J. K., and Pease, L. R. (1989). Site-directed mutagenesis by overlap extension using the polymerase chain reaction. Gene 77, 51-59

Imagawa, M., Chiu, R., and Karin, M. (1987). Transcription factor AP-2 mediates induction by two different signal-transduction pathways: protein kinase $C$ and CAMP. Cell 51, 251-260.

Kadowaki, Y., Toyoshima, K., and Yamamoto, T. (1992). Ear3/COUP. TF binds most tightly to a response element with tandem repeat separated by one nucleotide. Biochem. Biophys. Res. Commun. 183, 492498.

Kastner, P., Brand, N., Krust, A., Leroy, P., Mendelsohn, C., Petkovitch, M., Zelent, A., and Chambon, P. (1992). Retinoic acid nuclear receptors. In Developmental Patterning of the Vertebrate Limb, J. R. Hinchliffe et al., eds. (New York: Plenum Press), pp. 75-88.

Kliewer, S. A., Umesono, K., Heyman, R. A., Mangelsdorf, D. J., Dyck, J. A., and Evans, R. M. (1992a). Retinoid X receptor-COUP-TF interactions modulate retinoic acid signaling. Proc. Natl. Acad. Sci. USA 89 1448-1452.

Kliewer, S. A., Umesono, K., Mangelsdort, D. J., and Evans, R. M. (1992b). Retinoid $X$ receptor interacts with nuclear receptors in retinoic acid, thyroid hormone and vitamin $D_{3}$ signalling. Nature $355,446-449$. Kumar, V., Green, S., Staub, A., and Chambon, P. (1986). Localisation of the oestradiol-binding and putative DNA-binding domains of the human oestrogen receptor. EMBO J. 5, 2231-2236.

Leid, M., Kastner, P., Lyons, R., Nakshatri, H., Saunders, M., Zacharewski, T., Chen, J.-Y., Staub, A., Garnier, J.-M., Mader, S., and Chambon, P. (1992). Purification, cloning, and RXR identity of the HeLa cell factor with which RAR or TR heterodimerizes to bind target sequences efficiently. Cell 68, 377-395.

Leroy, P., Nakshatri, H., and Chambon, P. (1991a). Mouse retinoic acid receptor $\alpha 2$ isoform is transcribed from a promoter that contains a retinoic acid response element. Proc. Natl. Acad. Sci. USA 88, 1013810142

Leroy, P., Krust, A., Zelent, A., Mendelsohn, C., Garnier, J.-M., Kastner, P., Dierich, A., and Chambon, P. (1991b). Multiple isoforms of the mouse retinoic acid receptor $\alpha$ are generated by alternative splicing and differential induction by retinoic acid. EMBO J. 10, 59-69.

Leroy, P., Krust, A., Kastner, P., Mendelsohn, C., Zelent, A., and Chambon, P. (1992). Retinoic acid receptors. In Retinoids in Normal Development and Teratogenesis, G. Morriss-Kay, ed. (Oxford: Oxford University Press), pp. 7-25.

Levin, A. A., Sturzenbecker, L. J., Kazmer, S., Bosakowski, T., Huselton, C., Allenby, G., Speck, J., Kratzeisen, C., Rosenberger, M., Lovey, A., and Grippo, J. F. (1992). 9-cis retinoic acid steroisomer binds and activates the nuclear receptor RXRa. Nature 355, 359-361.

Libby, P. R., and Bertran, J. S. (1982). Lack of intracellular retinoidbinding proteins in a retinol-sensitive cell line. Carcinogenesis $3,481-$ 484.

Lotan, A. (1980). Effects of vitamin A and its analogs (retinoids) on normal and neoplastic cells. Biochim. Biophys. Acta 605, 33-91.

Lucas, P. C., O'Brien, R. M., Mitchell, J. A., Davis, C. M., Imai, E., Forman, B. M., Samuels, H. H., and Granner, D. K. (1991). A retinoic acid response element is part of a pleiotropic domain in the phosphoenolpyruvate carboxykinase gene. Proc. Natl. Acad. Sci. USA 88, 2184-2188.

Luckow, B., and Schütz, G. (1987). CAT constructions with multiple unique restriction sites for the functional analysis of eukaryotic promoters and regulatory elements. Nucl. Acids Res. 105, 5490. 
Maden, M. (1991). Retinoid-binding proteins in the embryo. Semin. Dev. Biol. 2, 161-170.

Maden, M., Ong, D. E., Summerbell, D., and Chytil, F. (1988). Spatial distribution of cellular protein binding to retinoic acid in the chick limb bud. Nature 335, 733-735.

Maden, M., Ong, D. E., Summerbell, D., and Chytil, F. (1989). The role of retinoid-binding proteins in the generation of pattern in the developing limb, the regenerating limb and the nervous system. Development (Suppl.) 107, 109-119.

Mader, S., Leroy, P., Chen, J.-Y., and Chambon, P. (1992). Multiple parameters control the selectivity of nuclear receptors for their re sponse elements: selectivity and promiscuity in response element recognition by RARs and RXRs. J. Biol. Chem. 267, in press.

Mangelsdorf, D. J., Ong, E. S., Dyck, J. A., and Evans, R. M. (1990). Nuclear receptor that identifies a novel retinoic acid response pathway. Nature 345, 224-229.

Mangelsdorf, D. J., Umesono, K., Kliewer, S. A., Borgmeyer, U., Ong, E. S., and Evans, R. M. (1991). A direct repeat in the cellular retinolbinding protein type II gene confers differential regulation by RXP and RAR. Cell 66, 555-561.

Mangelsdorf, D. J., Borgmeyer, U., Heyman, R. A., Zhou, J. Y., Ong, E. S., Oro, A. E., Kakizuka, A., and Evans, R. M. (1992). Characterization of three RXR genes that mediate the action of 9-cis retinoic acid. Genes Dev. 6, 329-344.

Marks, M. S., Hallenbeck, P. L., Nagata, T., Segars, J. H., Appella, E., Nikodem, V. M., and Ozato, K. (1992). H-2RIIBP (RXRB) heterodimerization provides a mechanlsm for comblnatorial diversity in the regulation of retinoic acid and thyroid hormone responsive genes. EMBO J. 11, 1419-1435.

Mendelsohn, C., Ruberte, E., and Chambon, P. (1992). Retinoids in vertebrate limb development. Dev. Biol. 152, 50-61.

Mitchell, P. J., Wang, C., and Tjian, R. (1987). Positive and negative regulation of transcription in vitro: enhancer-binding protein AP-2 inhibited by SV40 T antigen. Cell 50, 847-861.

Năăr, A. M., Boutin, J.-M., Lipkin, S. M., Yu, V. C., Holloway, J. M., Glass, C. K., and Rosenfeld, M. G. (1991). The orientation and spacing of core DNA-binding motifs dictate selective transcriptional responses to three nuclear receptors. Cell $65,1267-1279$.

Nagpal, S., Saunders, M., Kastner, P., Durand, B., Nakshatri, H., and Chambon, P. (1992). Promoter context- and response element-dependent specificity of the transcriptional activation and modulating functions of retinoic acid receptors. Cell 70 , in press.

Nicholson, R. C., Mader, S., Nagpal, S., Leid, M., Rochette-Egly, C., and Chambon, $P .(1990)$. Negative regulation of the rat stromelysin gene promoter by retinoic acid is mediated by an AP1 binding site. EMBO J. 9, 4443-4454

Petkovich, M., Brand, N. J., Krust, A., and Chambon, P. (1987). A human retinoic acid receptor which belongs to the family of nuclear receptors. Nature 330, 444-450.

Robertson, M. (1987). Retinoic acid receptor: towards a biochemistry of morphogenesis. Nature 330, 420-421.

Rochette-Egly, C., Lutz, Y., Saunders, M., Scheuer, I., Gaub, M.-P., and Chambon, $P$. (1991). Retinoic acid receptor $\gamma$ : specific immunodetection and phosphorylation. J. Cell Biol. 115, 535-545.

Rottman, J. N., Widom, R. L., Nadal-Ginard, B., Mahdavi, V., and Karathanasis, S. K. (1991). A retinoic acid-responsive element in the apolipoprotein Al gene distinguishes between two different retinoic acid response pathways. Mol. Cell. Biol. 11, 3814-3820

Rowe, A., Eager, N. S. C., and Brickell, P. M. (1991). A member of the RXR nuclear receptor family is expressed in neural-crest-derived cells of the developing chick peripheral nervous system. Development 111, 771-778.

Ruberte, E., Kastner, P., Dollé, P., Krust, A., Leroy, P., Mendelsohn, C., Zelent, A., and Chambon, P. (1991a). Retinoic acid receptors in the embryo. Semin. Dev. Biol. 2, 153-159.

Ruberte, E., Dolle, P., Chambon, P., and Morriss-Kay, G. (1991b). Retinoic acid receptors and cellular retinoid binding proteins. II. Their differential pattern of transcription during early morphogenesis in mouse embryos. Development 111, 45-60.
Ruberte, E., Friederich, V., Morriss-Kay, G., and Chambon, P. (1992). Differential distribution patterns of CRABP I and CRABP II transcripts during mouse embryogenesis. Development, in press.

Santoro, C., Mermod, N., Andrews, P. C., and Tjian, R. (1988). A family of human CCAAT-box-binding proteins active in transcription and DNA replication: cloning and expression of multiple cDNAs. Nature 334 , 218-224.

Saurat, J.-H., ed. (1990). Retinoids: 10 Years On (Basel: S. Karger). Sherman, M. I., ed. (1986). Retinoids and Cell Differentiation (Boca Raton, Florida: CRC Press).

Siegenthaler, G., and Saurat, J.-H. (1990). Natural retinoids: metabolism and transport in human epidermal cells. In Retinoids: 10 Years On, J.-H. Saurat, ed. (Basel: S. Karger), pp. 56-68.

Smith, S. M., Pang, K., Sundin, O., Wedden, S. E., Thaller, C., and Eichele, G. (1989). Molecular approaches to vertebrate limb morphogenesis. Development (Suppl.) 107, 121-131

Smith, W. C., Nakshatri, H., Leroy, P., Rees, J., and Chambon, P. (1991). A retinoic acid response element is present in the mouse cellular retinol binding protein I (mCRBPI) promoter. EMBO J. 10, 22232230 .

Stoner, C. M., and Gudas, L. J. (1989). Mouse cellular retinoic acid binding protein: cloning, complementary DNA sequence, and messenger RNA expression during the retinoic acid-induced differentiation of F9 wild type and RA-3-10 mutant teratocarcinoma cells. Cancer Res. 49, 1497-1504.

Sucov, H. M., Murakami, K. K., and Evans, R. M. (1990). Characterization of an autoregulated response element in the mouse retinoic acid receptor type $\beta$ gene. Proc. Natl. Acad. Sci. USA 87, 5392-5396.

Summerbell, D., and Maden, M. (1990). Retinoic acid, a developmental signalling molecule. Trends Neurosci. 13, 142-147.

Tabin, C. J. (1991). Retinoids, homeoboxes, and growth factors: toward molecular models for limb development. Cell 66, 199-217.

Umesono, K., Murakami, K. K., Thompson, C. C., and Evans, R. M. (1991). Direct repeats as selective response elements for the thyroid hormone, retinoic acid, and vitamin $\mathrm{D}_{3}$ receptors. Cell 65, 1255-1266. Vasios, G. W., Gold, J. D., Petkovich, M., Chambon, P., and Gudas, L. J. (1989). A retinoic acld-responsive element is present in the 5 flanking region of the laminin 81 gene. Proc. Natl. Acad. Sci. USA 86, 9099-9103.

Vasios, G., Mader, S., Gold, J. D., Leid, M., Lutz, Y., Gaub, M.-P., Chambon, $P_{\text {., }}$ and Gudas, L. (1991). The late retinoic acid induction of laminin B1 gene transcription involves RAP binding to the responsive element. EMBO J. 10, 1149-1158.

Wei, L. N., Blaner, W. S., Goodman, D. S., and Nguyen-Huu, M. C. (1989). Regulation of the cellular retinoid-binding proteins and their messenger ribonucleic acids during P19 embryonal carcinoma cell differentiation induced by retinoic acid. Mol. Endocrinol. 3, 454-463. Wei, L. N., Tsao, J. L., Chu, Y. S., Jeannotte, L., and Nguyen-Huu, M. C. (1990). Molecular cloning and transcriptional mapping of the mouse cellular retinoic acid-binding protein gene. DNA Cell Biol. 9 , 471-478.

Wei, L. N., Chen, G. J., Chu, Y. S., Tsao, J. L., and Nguyen-Huu, M. C. (1991). A 3 kb sequence from the mouse cellular retinoic-acid-binding protein gene upstream region mediates spatial and temporal lac $Z$ expression in transgenic mouse embryos. Development 112, 847-854. Yu, V. C., Delsert, C., Andersen, B., Holloway, J. M., Devary, O., Näăr, A. M., Kim, S. Y., Boutin, J.-M., Glass, C. K., and Rosenfeld, M. G. (1991). RXRB: a coregulator that enhances binding of retinoic acid, thyroid hormone, and vitamin $D$ receptors to their cognate response elements. Cell 67, 1251-1266.

Zelent, A., Krust, A., Petkovich, M., Kastner, P., and Chambon, P. (1989). Cloning of murine $\alpha$ and $\beta$ retinoic acid receptors and a novel receptor $\gamma$ predominantly expressed in skin. Nature 339, 714-717.

Zelent, A., Mendelsohn, C., Kastner, P., Krust, A., Garnier, J.-M., Ruffenach, F., Leroy, P., and Chambon, P. (1991). Differentially expressed isoforms of the mouse retinoic acid receptor $\beta$ are generated by usage of two promoters and alternative splicing. EMBO J. 10, 7181.

Zhang, X. K., Hoffmann, B., Tran, P. B. V., Graupner, G., and Pfahl, 
All-Trans and 9-Cis RA-Induced Expression of CRABPII by RAR-RXR Heterodimers 85

M. (1992). Retinoid $X$ receptor is an auxiliary protein for thyroid hormone and retinoic acid receptors. Nature $355,441-446$.

CenBank Accession Number

The accession number for the sequence reported in this paper is L01528.

\section{Note Added in Proof}

The data listed as unpublished by M. T. Bocquel et al. is now in press: Allenby, G., Bocquel, M. T., Saunders, M., Kazmer, S., Speck, J., Rosenberger, M., Lovey, A., Kastner, P., Grippo, J. F., Chambon, P., and Levin, A. A. (1992). Retinoic acid receptors (RARs) and retinoid $X$ receptors (RXRs): Interactions with endogenous retinoic acids. Proc. Natl. Acad. Sci. USA 89, in press. 